\title{
Changes on available phosphorus and total nitrogen contents from soil around roots of two desert plants
}

\author{
Guo-Hua Chang ${ }^{1}$, Wang-jiang Wang ${ }^{1}$, Zhuo-Xin Yin ${ }^{1}$, Bin Yue ${ }^{1}$, Jin-xiang Wang ${ }^{1, *}$, and Tian-peng Gao ${ }^{1,2, *}$ \\ ${ }^{1}$ School of Geography and Environmental Engineering, Lanzhou City University, The Engineering Research Center of Mining Pollution \\ Treatment and Ecological Restoration of Gansu Province, Gansu 730070, China \\ ${ }^{2}$ College of Biological and Environmental Engineering, Xi'an University, Xi'an 710065, China
}

\begin{abstract}
In order to understand variation characteristics of the soil available phosphorus and total nitrogen (TN) content around the roots of typical desert plants Peganum harmala Linn. (PHL) and Asterothamnus centrali-asiaticus (AC), which are widely distributed in Jinchang mining area of Gansu Province, the soil samples around the roots of the two plants were collected, and the contents of available phosphorus and TN were analyzed. The results showed that the change trend of soil available phosphorus content was not the same in the range of 0-60 cm around the roots of PHL and AC. In most areas the change of available phosphorus content in the soil from around the root of PHL was U-shaped, and the content of phosphorus around the roots of AC increased firstly and then decreased, while the change trends of TN content around $\mathrm{AC}$ was decreased gradually.
\end{abstract}

\section{Introduction}

Phosphorus and nitrogen play an important role in the growth and metabolism of plants. To determine available phosphorus and nitrogen in soil is helpful for people to understand the supply of phosphorus and nitrogen in soil and to improve plant growth [1]. The absorption and utilization rate of nutrients, the demand for nutrients, and $\mathrm{N}$ and $\mathrm{P}$ nutrient levels provided by soil in the growing environment of plants are important factors which cause the differences in growth rate, reproductive output and competitiveness among plants [2, 3]. With the rapid growth of plant, it needs to require a large amount of rRNA for synthesizing protein, and rRNA contains a large amount of $\mathrm{P}$, which would cause low $\mathrm{C} / \mathrm{P}$ ratio and $\mathrm{N} / \mathrm{P}$ ratio in the plants or tissues with high growth rate [3]. The contents of $\mathrm{C}, \mathrm{N}$ and $\mathrm{P}$ and the ratio of elements in plant body could not only reflect the status of nutrient absorption and utilization, but also indicate the relative growth rate and nutrition strategy of plants [2-5]. The study on plant enrichment of heavy metals in nickel copper deposit area of Gansu Province showed that Peganum harmala Linn. (PHL) and Asterothamnus centrali-asiaticus (AC) were widely distributed here and could enrich copper and nickel [6]. The two plants are typical local desert plants. In Gansu province, Jinchang city has rich mineral resources and rich nickel ore reserves. The exploitation and utilization of the mine not only brings economic benefits to the local, but also brings many environmental problems [7]. It is needed to control soil pollution and restore vegetation in mining area for cherishing and rationally utilizing land resources, but also for environmental protection.

Peganum harmala is a perennial herb, which has the typical characteristics of xerophyte, such as developed root system, deeply split leaves and thin lobes, and strong drought resistance. In addition, the plant grows luxuriantly and plays an important role in wind resistance, sand fixation and soil erosion prevention, and improving desert environment in Northwest China [8-10]. In recent years, the research on the Peganum harmala mainly focused on the stress resistance, active components and pharmacological activities [11, 12].

Asterothamnus centrali-asiaticus is a semi shrubby desert plant, which appears in the desert and desert steppe zone, and is mainly found in loose sandy alluvial and proluvial soil. This plant has strong characteristics of drought resistance, cold resistance, barren resistance, sand burial resistance and wind erosion resistance, which plays an important role in maintaining the desert grassland ecosystem [13].

In order to better understand the growth characteristics of the two plants in the region, the content of available phosphorus and TN in the soil around the roots of the two plants was measured for providing a reliable basis for the recovery of vegetation in the arid nickel-copper mining area.

\section{Materials and methods}

Soil samples were collected from Jinchang City, Gansu Province [6]. 7 sampling areas were selected (A, 38 $28^{\prime}$ $43.89^{\prime \prime} \mathrm{N}, 102^{\circ} 14^{\prime} 00.50^{\prime \prime} \mathrm{E}$; B, $38^{\circ} 28^{\prime} 52.14^{\prime \prime} \mathrm{N}, 102^{\circ} 14^{\prime}$

\footnotetext{
${ }^{*}$ Corresponding author: zkgtp@163.com
} 
25.44" E; C, $38{ }^{\circ} 27^{\prime} 17.77 " \mathrm{~N}, 102^{\circ} 13^{\prime}$ 21.69" E; D, $38^{\circ} 30^{\prime} 57.5^{\prime \prime} \mathrm{N}, 102^{\circ} 09^{\prime} 4.2^{\prime \prime} \mathrm{E}$; E, $38^{\circ} 39^{\prime} 16.23^{\prime \prime} \mathrm{N}, 102^{\circ}$ $16^{\prime} 46.32^{\prime \prime} \mathrm{E}$; F, $38^{\circ} 29^{\prime} 27.6^{\prime \prime} \mathrm{N}, 102^{\circ} 09^{\prime} 10.3^{\prime \prime} \mathrm{E} ; \mathrm{G}, 38^{\circ}$ $\left.33^{\prime} 49.3^{\prime \prime N}, 102^{\circ} 08^{\prime} 55.8^{\prime \prime} \mathrm{E}\right)$. Soil samples $(0 \sim 20 \mathrm{~cm})$ were collected at the horizontal direction of $0,20,40$, and $60 \mathrm{~cm}$ from the root of the two plants. The collected soil samples were dried indoors, and stones and debris were removed from samples, and then crushed. $2.500 \mathrm{~g}$ of the sample after $1 \mathrm{~mm}$ sieving was weighed. Then $0.5 \mathrm{~mol} \cdot \mathrm{L}^{-}$ ${ }^{1} \mathrm{NaHCO}_{3}(\mathrm{pH}=8.5)$ solution was added into the sample, followed by $30 \mathrm{~min}$ oscillation at constant temperature $(25$ $\pm 0.5{ }^{\circ} \mathrm{C}$ ), and then the sample was filtered immediately with a $0.22 \mu \mathrm{m}$ phosphor-free membrane. The available phosphorus content in the filtrate was determined by Mo$\mathrm{Sb}$ Anti-Spectrophotometer [14]. The available phosphorus content in the soil samples was expressed as $\mathrm{mg} \cdot \mathrm{kg}^{-1}$, and the results were expressed as the mean \pm standard deviation (SD). Soil samples were digested with concentrated sulfuric acid, and total nitrogen was determined by K9840 Automatic Kjeldahl nitrogen analyzer [15].

\section{Results and discussion}

\subsection{Changes on available phosphorus in soil around plants}

In the above areas, the content of phosphorus varied from $1.496 \mathrm{mg} \cdot \mathrm{kg}^{-1}$ to $38.619 \pm 2.293 \mathrm{mg} \cdot \mathrm{kg}^{-1}$ (Fig 1 and 2). The content of available phosphorus in most samples is relatively low based on the classification standard of soil available phosphorus content in soil of China [16].

Changes on available phosphorus in soil around the roots of PHL from different areas were showed in Fig. 1. Within the $60 \mathrm{~cm}$ growth radius of PHL in A area, the phosphorus content in the soil from the horizontal direction around the plant roots decreased first and then increased, and the lowest content of phosphorus was $1.496 \mathrm{mg} \cdot \mathrm{kg}^{-1}$ at $20 \mathrm{~cm}$. In B area, the highest phosphorus content was $20.961 \pm 0.677 \mathrm{mg} \cdot \mathrm{kg}^{-1}$ within the growth radius of $60 \mathrm{~cm}$ around the root of PHL. In area C, the phosphorus content around PHL decreased first and then increased, and the lowest phosphorus content was $8.742 \pm$ $0.730 \mathrm{mg} \cdot \mathrm{kg}^{-1}$ at $40 \mathrm{~cm}$. The content of phosphorus around PHL in area D decreased gradually with increasing distance, and the highest content of phosphorus was 8.411 $\pm 1.239 \mathrm{mg} \cdot \mathrm{kg}^{-1}$ at $0 \mathrm{~cm}$. The maximum value of phosphorus content around PHL was $24.218 \pm 1.077$ $\mathrm{mg} \cdot \mathrm{kg}^{-1}$ at $60 \mathrm{~cm}$ in area E. The content of phosphorus around PHL showed a gradually decreasing trend in area F. Within the growth radius of $60 \mathrm{~cm}$ of PHL in G area, the phosphorus content decreased first and then increased, and the lowest value was $8.251 \pm 0.251 \mathrm{mg} \cdot \mathrm{kg}^{-1}$ at $40 \mathrm{~cm}$.

It can be seen that in most areas, the content of available phosphorus in the soil samples around the roots of PHL decreased first and then increased with the increase of the distance, and the content of phosphorus around the roots of the plant was relatively high. The phenomenon may be closely related to the microbial activities in the rhizosphere soil of the plant. Cheng et al. researched that the characteristics of bacterial communities inrhizosphere soil of $P$. harmala in a desert steppe in Baiyin, Gansu Province, and their results showed that there were significant differences in the composition and structure of rhizosphere microbial community from soil of $P$. harmala and its surrounding desert steppe soil. The number and diversity index of microorganisms in rhizosphere soil were significantly higher than those in non rhizosphere soil. The dominant bacteria in rhizosphere soil were consisted of $30.01 \%$ Actinobacteria, $\quad 23.98 \%$ Proteobacteria, $\quad 11.53 \%$ Bacteroidetes and $10.19 \%$ Acidobacteria, and the dominant soil bacterial community in the surrounding desert steppe were composed of 55.05\% Actinobacteria, $21.11 \%$ Proteobacteria and $6.07 \%$ Acidobacteria [9]. The result indicated that desert plants could increase the number and activity of rhizosphere microorganisms, promote the accumulation and transformation of soil nutrients, and play an important role in maintaining the function of desert ecosystem.

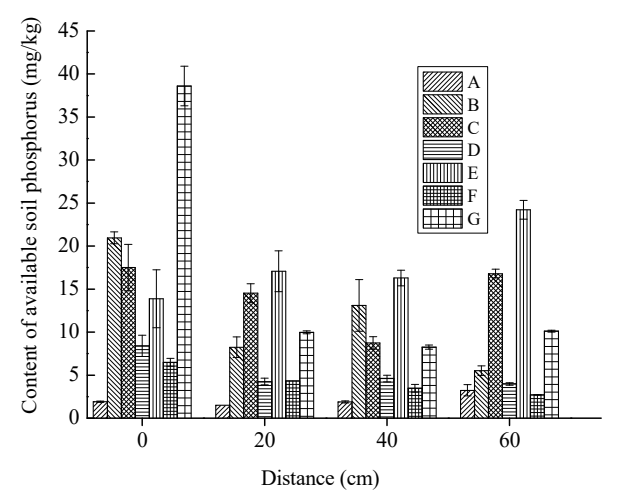

Figure 1. Changes on available phosphorus in soil around the roots of PHL from different areas.

Changes on available phosphorus in soil around the roots of AC were showed in Fig. 2. In the above areas, AC was not found within 100 meters of the collection point in area $\mathrm{A}$. The average phosphorus content near $\mathrm{AC}$ in area $B$ was $22.875 \mathrm{mg} \cdot \mathrm{kg}^{-1}$. The phosphorus content near the plant in area $\mathrm{C}$ was the lowest among all areas, with an average of $5.677 \mathrm{mg} \cdot \mathrm{kg}^{-1}$.

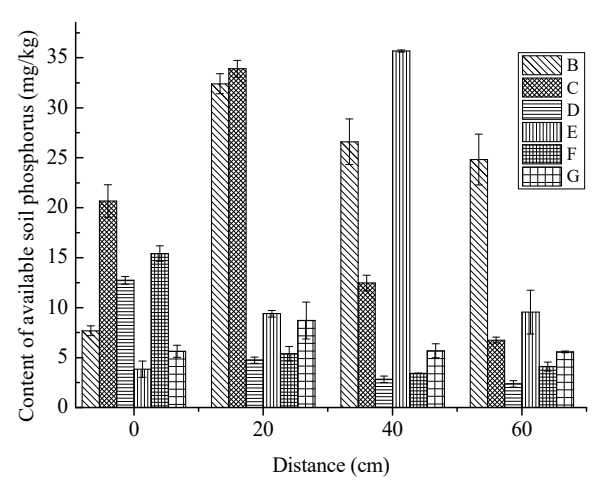

Figure 2. Changes on available phosphorus in soil around the roots of $\mathrm{AC}$ from different areas.

The results showed that the change trend of the mean value of phosphorus content from all areas around PHL decreased firstly and then increased with increasing 
distance, with the lowest phosphorus content of $8.051 \pm$ $0.838 \mathrm{mg} \cdot \mathrm{kg}^{-1}$ at $40 \mathrm{~cm}$; and that of the mean value of phosphorus content from all areas around AC increased first and then decreased with increasing distance, with the highest value of phosphorus content $15.760 \pm 0.844$ $\mathrm{mg} \cdot \mathrm{kg}^{-1}$ at $20 \mathrm{~cm}$ (Fig 3). The content of available P at 60 $\mathrm{cm}$ around PHL was close to that of $\mathrm{AC}$, and their values of available $\mathrm{P}$ were $9.511 \pm 0.434$ and $8.868 \pm 0.979$ $\mathrm{mg} \cdot \mathrm{kg}^{-1}$, respectively (Fig. 3).

The average values of all the measured points from all the areas of these two plants were close to each other, with the values of $10.379 \pm 0.891 \mathrm{mg} \cdot \mathrm{kg}^{-1}$ for PHL and 12.519 $\pm 0.827 \mathrm{mg} \cdot \mathrm{kg}^{-1}$ for AC. The results also indicated that the variation characteristics of available phosphorus content around the roots of different plants were different, which might be closely related to the characteristics of plant roots and the characteristics of microorganisms related to the roots of plants.

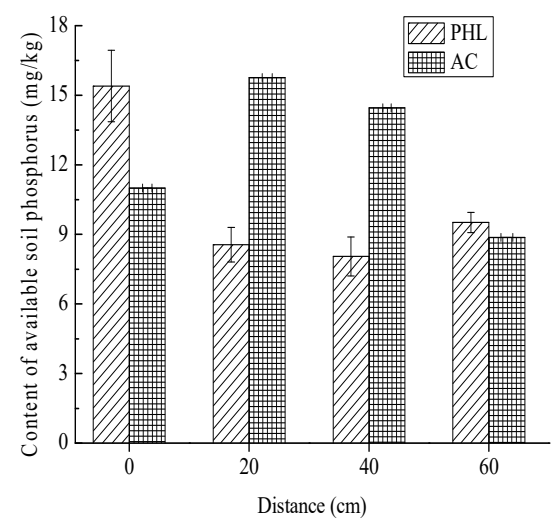

Figure 3. The average values of phosphorus content in soil around the two plants from all the areas.

\subsection{Changes on TN in soil around plants}

In the above areas, the content of TN varied from $0.11 \%$ to $0.020 \%$ (Fig 4 and 5). The content of TN in E area which is located in desert area is relatively lowest and there is the highest TN content in $\mathrm{C}$ area which is close to farmland.

Changes on TN in soil around the roots of PHL from different areas were showed in Fig. 4. Within the $60 \mathrm{~cm}$ growth radius of PHL in A area, the TN content in the soil from the horizontal direction around the plant roots decreased first and then increased, and the lowest content of phosphorus was $0.37 \%$ at $40 \mathrm{~cm}$. In area $\mathrm{C}$, the phosphorus content around PHL decreased first and then increased, and the lowest phosphorus content was $0.082 \%$ at $20 \mathrm{~cm}$. The maximum value of phosphorus content around PHL was $0.092 \%$ at $0 \mathrm{~cm}$ around PHL in D area (at tailing dam). The content of phosphorus around PHL showed a gradually decreasing trend with increasing distance, in area $F$ and $G$ areas.

Changes on TN in soil around the roots of $\mathrm{AC}$ were showed in Fig. 5. The average TN contents in area $\mathrm{C}$ (near farmland) and D areas were higher than other areas. The $\mathrm{TN}$ contents near the plant in most areas decreased with increasing distance.
The results showed that the change trend of the mean TN content from all areas around PHL decreased firstly and then increased with increasing distance, with the lowest TN content of $0.043 \%$ at $40 \mathrm{~cm}$; while the TN content around AC decreased gradually with increasing distance, and the highest content of TN was $0.063 \%$ at 0 $\mathrm{cm}$ (Fig 6). While, the average TN values of all the measured points from all the areas of these two plants were no significant difference between the two plants.

The variation characteristics of nutrients such as nitrogen and phosphorus around plant roots are closely related to the growth characteristics of plant roots and the interaction characteristics between roots and microorganisms. The variation characteristics of nitrogen and phosphorus around the roots of different plants may be different.

Li et al. found that the rhizosphere soil and the nonrhizosphere soil of seven typical plants from the Loess Plateau had significant differences in both soil microbial biomass and basal respiration, and the contents of organic carbon and nitrogen in rhizosphere soil were higher than those in non rhizosphere soil [17].

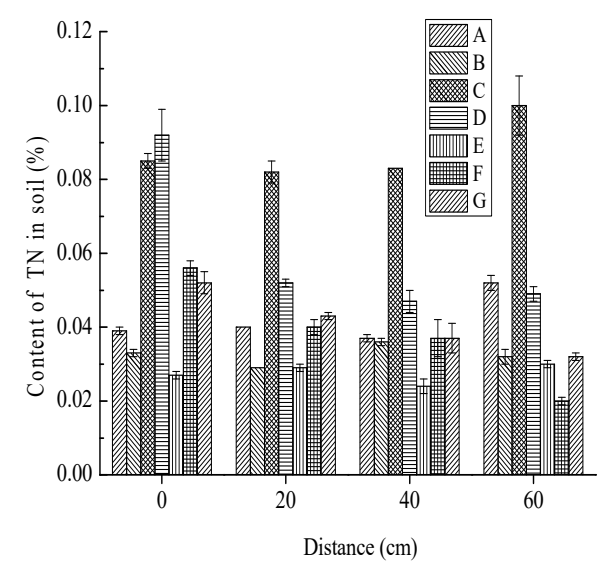

Figure 4. Changes on TN in soil around the roots of PHL from different areas.

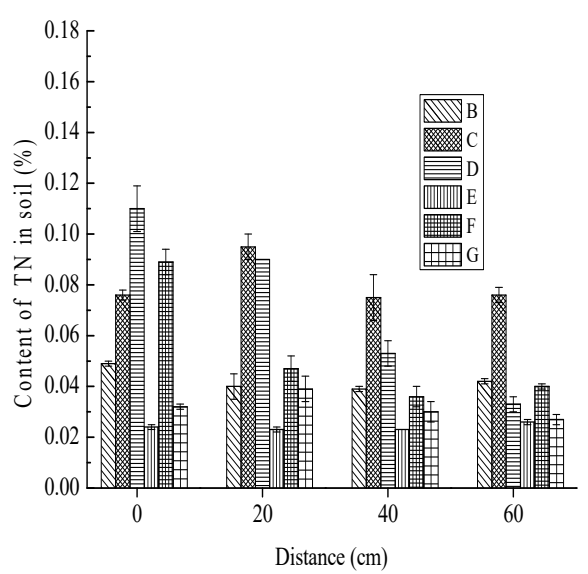

Figure 5. Changes on $\mathrm{TN}$ in soil around the roots of $\mathrm{AC}$ from different areas. 


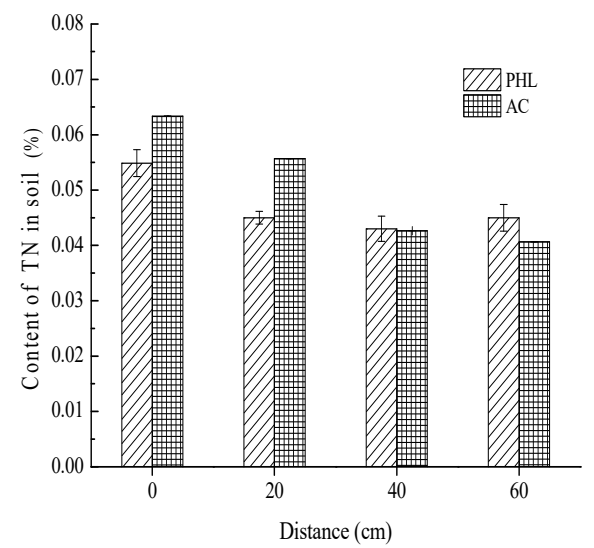

Figure 6. The average values of TN in soil around the two plants from all the areas.

\section{Conclusions}

On the whole, the content of soil available phosphorus in the study area is in the lower middle level. Within the range of $60 \mathrm{~cm}$ around the roots of the two plants, the change trend of average available phosphorus content in soil samples around AC is not the same as that of PHL. Around the two roots of AC and PHL, both of the highest values of TN content showed at $0 \mathrm{~cm}$, and the former was higher than that of the latter. Generally, the change trends of TN content was similar with the available phosphorus content in soil around the roots of PHL, while the change trends on TN content around AC was not the same with the available phosphorus content in soil.

\section{Acknowledgment}

This research was funded by the National Natural Science Foundation of China (31860176), Science and technology project of Gansu Province (20YF3FA037), Shaanxi Province (2020ZDLSF06-06), Research Project of Universities from Gansu (2019B-169, 20JR5RA210 and 20JR10RA286), and the project of XAWLXYKYTD012.

\section{References}

1. Y. Luo, Y. Chen, Q.W. Peng, K.H. Li, A. Mohammat, W.X. Han. Nitrogen and phosphorus resorption of desert plants with various degree of propensity to salt in response to drought and saline stress, Ecological Indicators, 125 (2021), 107488.

2. C. Liu, Y. Wang, Wang N., G.X. Wang. Advances research in plant nitrogen, phosphors and their stoichiometry in terrestrial ecosystems: a review. Chinese Journal of Plant Ecology, 36 (2012), 12051216.

3. W. Chen, J.H. Wang, X.Y. Chen, N.H. Guo, J.L. Su, X.Y. Zhou, R. Huang. The carbon, nitrogen and phosphorus stoichiometric characteristics of invasive species rhynchelytrum repens and their nutrition strategy. Journal of Ecology and Rural Environment, 36 (2020), 1293-1300.

4. B.O.L. Demars, A.C. Edwards. Tissue nutrient concentrations in freshwater aquatic macrophytes: high inter-taxon differences and low phenotypic response to nutrient supply. Freshwater Biology, 52 (2010), 2073-2086.

5. S.J. Ren, G.R. Yu, B. Tao, S.Q. Wang. Leaf nitrogen and phosphorus stoichiometry across 654 terrestrial plant species in NSTEC. Chinese Journal of Environmental Science, 28 (2007), 2665-2673.

6. G.H. Chang, T.P. Gao, Q. Zhang, Y.Q. Chen, X.S. Tai, M.K. Chen. Study on the characteristics of heavy metals concentrated in native plants of Jinchuan mining area. Environmental Science and Engineering, 1 (2019), 842-849.

7. H.X. Ding, Z.R. Nan, X.W. Liu, Y. Li, S.L. Wang, S. Qin, Z.J. Zhao. Characteristics of selected heavy metal pollution in suburb cropland, Jinchang City, Gansu, China. Journal of Agro-Environment Science. 27 (2008), 2183-2188.

8. J. Ma, X.L. Wang. The species and distribution of genus Peganum L. in the desert area of China. J. Desert Res., 18 (1998), 131-136.

9. L. Cheng, J.X. Chen, Y.L. Li, Y.G. Wang, Y. T. Zhou, Y. Zhang. Diversity of bacterial communities in rhizosphere soil of Peganum harmala L. in desert steppe. Arid Zone Research, 35 (2018), 977-983.

10. M.Z. Xia, Y. Zhang, J.Y. Yu, F.Q. Zhang. Transcriptome analysis for leaves of Peganum mulstecutm. Guihaia, 39 (2019), 1-11.

11. M.N. Ansari. Assessment of antidiarrheal, antispasmodic and antimicrobial activities of methanolic seeds extract of Peganum harmala L. (Nitrariaceae). Journal of Pharmaceutical Research International, 2020, 74-82.

12. Z.N. Wu, N.H. Chen, Q. Tang, S. Chen, Z.C. Zhan, Y.B. Zhang, G.C. Wang, Y.L. Li, W.C. Ye. $\beta$ carboline alkaloids from the seeds of Peganum harmala and their anti-HSV-2 virus activities. Organic Letters. 22 (2020), 7310-7314.

13. Y.Q. Chai, Z.Z. Cao, B.R. Liu. Community characteristics of Asterothamnus centrali-asiaticus and Gymnocarpos przewalskii in the Subei Desert of Hexi Corridor, Gansu. Scientia Silvae Sinicae. 47 (2011), 166-171.

14. Ministry of agriculture of the people's Republic of China, the agricultural industry standard of the people's Republic of China NY / T1121.7-2014 Soil testing-Part 7: Method for determination of available phosphorus in soil. Beijing, 2014.

15. National environmental protection standard of the People's Republic of China. Soil qualityDetermination of total nitrogen-Modified Kjeldahl method (HJ717-2014), 2014.

16. National Soil Census Office. Soil in China. Beijing: China Agricultural Publishing House, 1995. 
17. G.H. Li, Q.F. Chen, Y.M. Huang, S.S. An, F.L. Zheng, L.D. Chen. Soil microbial biomass C, N, P and basal respiration in rhizosphere soil of typical plants on the Loess Plateau. Acta Ecologica Sinica, 30, (2010), 976-983. 